\title{
High Failure Rate after Beta-tricalcium Phosphate Grafting for the Treatment of Femoral Head Osteonecrosis: a Retrospective Analysis
}

Pei Liu

Beijing University of Chinese Medicine

\section{Xiao-hong Mu}

Beijing University of Chinese Medicine Affiliated Dongzhimen Hospital

\section{Hua-chen Yu}

Graduate School of Peking Union Medical College

\section{Guan Jian-lei}

Beijing University of Chinese Medicine

\section{Zhao-hui Liu}

China-Japan Friendship Hospital

Wei-guo Wang

China-Japan Friendship Hospital

\section{Qi-dong Zhang}

China-Japan Friendship Hospital

Wanshou Guo ( $\nabla$ cjfh2020@163.com )

China-Japan Friendship Hospital

\section{Research article}

Keywords: Osteonecrosis of the femoral head, Beta-tricalcium phosphate, Head-preserving surgery

Posted Date: January 14th, 2020

DOI: https://doi.org/10.21203/rs.2.20868/v1

License: (c) (i) This work is licensed under a Creative Commons Attribution 4.0 International License. Read Full License

Version of Record: A version of this preprint was published at BMC Musculoskeletal Disorders on April 27th, 2020. See the published version at https://doi.org/10.1186/s12891-020-03291-5.

\section{EDITORIAL NOTE:}

24 January 2022: The published version of this preprint was retracted from BMC Musculoskeletal Disorders on 24 May 2021. The retraction notice can be found here. Research Square has withdrawn this preprint. 


\section{Abstract}

Background: Non-vascularized bone grafting is a promising head-preserving technique for younger patients diagnosed as non-traumatic osteonecrosis of the femoral head (NONFH). Among the various types of bone grafting techniques, "lightbulb" procedure grafting with synthetic bone substitute is an attractive option. We aimed to assess the effectiveness of using beta-tricalcium phosphate ( $\beta$-TCP) for the treatment of pre-collapse and early post-collapse lesions NONFH.

Methods: From April 2010 to June 2014, 33 patients (47 hips) with NONFH were treated using the afore-mentioned technique. The clinical and radiological outcomes were compared between pre- and post-operation. Harris hip score (HHS) was used to evaluate the clinical results, and Association Research Circulation Osseous (ARCO) stage was applied to assess the radiological outcomes.

Results: After 5 years' follow-up, the failure rate of using $\beta$-TCP grafting was accounting for $74.5 \%$. 2 hips collapsed more than $2 \mathrm{~mm}$ were awaiting for THA, and 33 of the 47 hips had converted to THAs in an average time to failure of $24.1 \pm 14.6$ months postoperatively. Meanwhile, only 4 hips survived without collapse, and 8 hips collapsed less than $2 \mathrm{~mm}$. After surgery, the time onset of head collapse was $3.6 \pm 1.4$ months on average, and the first conversion to THA was performed at 5 months postoperative.

Conclusions: Our results suggest that "light-bulb" procedure grafting with $\beta$-TCP sticks presented with a high failure rate in the early postoperative period. It is not proposed for the treatment of pre-collapse and early post-collapse lesions NONFH.

\section{Background}

Non-traumatic osteonecrosis of femoral head (NONFH) is a devastating condition associated with apoptosis of the osteocytes and the bone marrow, which has a natural history of relentless progressive necrosis leading to fracture of subchondral bone plate, collapse of femoral head articular surface, and eventual premature osteoarthritis of hip [1,2]. Meanwhile, NONFH is a challenging disease as it frequently disturbs young patients between second and fifth decades, the etiologies and risk factors are multiple, the pathogenesis is unknown, early diagnosis is difficult, and the successful treatment is undetermined [3]. Therapeutic methods have been developed for the treatment of NONFH can be assigned into three categories: non-surgical management, head-preserving surgery and hip-replacing procedures. Being a progressive disease, non-surgical management is generally unsuccessful. Total hip arthroplasty (THA) is also not a favorable treatment for young patients due to their long life expectancy. Therefore, many head-preserving procedures are proposed to protect the involved hip from collapse, which include a large single or multiple small holes core decompression (CD) [4, 5], osteotomies in various types $[6,7]$, and bone grafting in different methods $[8,9]$.

The "light-bulb" technique initially described by Rosenwasser, in which a window is made at the femoral head neck junction, allows the debridement of necrotic tissue then subsequent bone grafting [10]. Donor bone tissues can be divided into autograft, allograft, and synthetic bone substitute. Autologous bone graft is considered as the gold standard, but it may require additional surgeries, and is related with donor-site complications [11]. Allograft is restrained by disease transmission, possible immune rejection, and lower incorporation rate compared to autograft [12]. Some synthetic bone substitutes through mimicking the structure, properties, and function of natural bone have been used as feasible alternatives to support the subchondral bone of femoral head, and to avoid donor-site morbidity [13]. Characterized by easy biodegradation and high osteoconduction [14], beta-tricalcium phosphate ( $\beta$-TCP) is used to refill the bone defect and provide initial mechanical support for ONFH in clinical practice [15].

We hypothesized that "light-bulb" procedure grafting with $\beta$-TCP for the treatment of pre-collapse and early post-collapse lesions NONFH could alleviate pain, stimulate bone formation, support the subchondral bone and articular cartilage of femoral head, maintain a congruent hip, improve joint function, and if possible, defer or avert the requirement for THA. In this study, we report results of this management and clarify its value. 


\section{Patients And Methods}

This study was approved by the Ethics Committee of the China-Japan Friendship Hospital (2015-SFZX-N). We retrospectively reviewed all patients with symptomatic NONFH who underwent "light-bulb" procedure grafting with $\beta$-TCP sticks (Shanghai Bio-lu Biomaterials, Shanghai, China) in our institution between April 2010 and June 2014. We claimed no research fund to the present study from Bio-lu Biomaterials Co. Ltd.

The diagnosis of NONFH was drawn based on history, clinical symptoms, physical examination, related risk factors and imaging data. Necrotic lesions of the femoral head were graded according to the Association Research Circulation Osseous

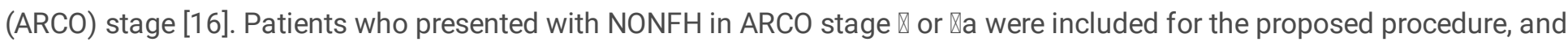
exclusion criteria were: (1) over-aged, mainly above 50 years; (2) unable to stop corticosteroids administration due to corticosteroid-dependent diseases; (3) failed to quit alcohol abuse.

Demographic patient data were collected from our hospital medical registry. In total, 37 patients with NONFH were treated with the recommended technique, and 4 of these patients were lost to follow-up. Finally, 33 patients (47 hips; 6 in female), with a mean age of $36.3 \pm 8.0$ years (range 23 years to 49 years) at the time of surgery were included. The risk factors included excessive intake of alcohol (consuming $>400 \mathrm{~mL}$ weekly) in 11 patients (17 hips), corticosteroids ( $2 \mathrm{~g}$ or more of systemic corticosteroids administered over a 3-month period minimum) in 19 patients (26 hips), and idiopathic in 3 patients (4 hips). Detailed information can be seen in Table 1.

Table 1

Demographic characteristics of patients with NONFH

\begin{tabular}{|ll|}
\hline Total patient number & $\mathbf{4 7}$ hips (33 patients) \\
\hline Mean age at surgery & 36 years (23-49 years) \\
\hline Gender ratio & Male/Female $=27 / 6$ \\
\hline Involved hip & Unilateral/Bilateral $=33 / 14$ \\
\hline Risk factors & \\
\hline Corticosteroid & 19 patients (26 hips) \\
\hline Alcoholism & 11 patients (17 hips) \\
\hline Idiopathic & 3 patients (4 hips) \\
\hline
\end{tabular}


Table 2

Outcomes of patients treated with $\beta$-TCP grafting

\begin{tabular}{|c|c|c|c|c|c|c|c|c|c|}
\hline \multirow[t]{2}{*}{ Case } & \multirow[t]{2}{*}{ Gender/Age } & \multirow[t]{2}{*}{ Etiology } & \multirow[t]{2}{*}{ Laterality } & \multicolumn{2}{|c|}{ Preoperative } & \multicolumn{3}{|c|}{ Follow-up } & \multirow[t]{2}{*}{ Outcomes } \\
\hline & & & & $\begin{array}{l}\text { ARCO } \\
\text { stage }\end{array}$ & HHS & $\begin{array}{l}\text { ARCO } \\
\text { stage }\end{array}$ & HHS & Survival(months) & \\
\hline \multirow[t]{2}{*}{1} & $M / 26$ & Alcoholism & Right & $\triangle \mathrm{c}$ & 75 & $\nabla c$ & 80 & 70 & $\begin{array}{l}\text { No } \\
\text { progression }\end{array}$ \\
\hline & & & Left & $\bigotimes a$ & 60 & $\nabla c$ & 45 & 24 & THA \\
\hline \multirow[t]{2}{*}{2} & $\mathrm{~F} / 39$ & Corticosteroid & Right & $\mathbb{~} \mathrm{c}$ & 70 & $\bigotimes a$ & 70 & 60 & $\begin{array}{l}\text { Collapse } \leq \\
2 \mathrm{~mm}\end{array}$ \\
\hline & & & Left & $\bigotimes a$ & 67 & ( & 34 & 8 & THA \\
\hline 3 & $\mathrm{M} / 42$ & Alcoholism & Left & 『a & 69 & प & 42 & 22 & THA \\
\hline \multirow[t]{2}{*}{4} & $M / 46$ & Alcoholism & Right & $\triangle \mathrm{c}$ & 80 & $\triangle a$ & 75 & 60 & $\begin{array}{l}\text { Collapse } \leq \\
2 \mathrm{~mm}\end{array}$ \\
\hline & & & Left & 『a & 64 & ( & 34 & 8 & THA \\
\hline \multirow[t]{2}{*}{5} & $\mathrm{M} / 44$ & Alcoholism & Right & $\nabla c$ & 86 & प & 48 & 38 & THA \\
\hline & & & Left & $\bigotimes a$ & 59 & प & 45 & 38 & THA \\
\hline \multirow[t]{2}{*}{6} & $M / 23$ & Corticosteroid & Right & $\nabla c$ & 85 & प & 40 & 12 & THA \\
\hline & & & Left & $\nabla \mathrm{b}$ & 90 & ( & 44 & 12 & THA \\
\hline 7 & $\mathrm{~F} / 34$ & Corticosteroid & Right & $\mathbb{\nabla a}$ & 70 & प & 41 & 37 & THA \\
\hline \multirow[t]{2}{*}{8} & $\mathrm{M} / 31$ & Corticosteroid & Right & $\nabla c$ & 78 & $\nabla c$ & 64 & 21 & THA \\
\hline & & & Left & $\nabla b$ & 80 & ( & 41 & 21 & THA \\
\hline \multirow[t]{2}{*}{9} & $M / 42$ & Corticosteroid & Right & $\nabla c$ & 75 & Q & 40 & 5 & THA \\
\hline & & & Left & $\nabla b$ & 80 & $\nabla c$ & 59 & 5 & THA \\
\hline \multirow[t]{2}{*}{10} & $\mathrm{M} / 33$ & Corticosteroid & Right & $\nabla c$ & 69 & $\nabla c$ & 80 & 65 & $\begin{array}{l}\text { No } \\
\text { progression }\end{array}$ \\
\hline & & & Left & $\nabla b$ & 76 & $\nabla \mathrm{b}$ & 84 & 65 & $\begin{array}{l}\text { No } \\
\text { progression }\end{array}$ \\
\hline 11 & $\mathrm{M} / 37$ & Corticosteroid & Left & $\nabla c$ & 69 & $\triangle a$ & 80 & 75 & $\begin{array}{l}\text { Collapse } \leq \\
2 \mathrm{~mm}\end{array}$ \\
\hline \multirow[t]{2}{*}{12} & $\mathrm{M} / 32$ & Alcoholism & Right & $\nabla c$ & 73 & $\triangle a$ & 78 & 62 & $\begin{array}{l}\text { Collapse } \leq \\
2 \mathrm{~mm}\end{array}$ \\
\hline & & & Left & $\nabla c$ & 67 & $\bigotimes a$ & 80 & 62 & $\begin{array}{l}\text { Collapse } \leq \\
2 \mathrm{~mm}\end{array}$ \\
\hline 13 & $\mathrm{M} / 42$ & Corticosteroid & Right & $\mathbb{\nabla a}$ & 58 & $\nabla c$ & 39 & 34 & THA \\
\hline 14 & $\mathrm{M} / 27$ & Corticosteroid & Right & $\mathbb{~} \mathrm{c}$ & 67 & $\bigotimes a$ & 79 & 64 & $\begin{array}{l}\text { Collapse } \leq \\
2 \mathrm{~mm}\end{array}$ \\
\hline \multirow[t]{2}{*}{15} & $F / 49$ & Idiopathic & Right & 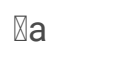 & 59 & प & 40 & 28 & THA \\
\hline & & & Left & 『a & 65 & प & 44 & 28 & THA \\
\hline
\end{tabular}




\begin{tabular}{|c|c|c|c|c|c|c|c|c|c|}
\hline \multirow[t]{2}{*}{ Case } & \multirow[t]{2}{*}{ Gender/Age } & \multirow[t]{2}{*}{ Etiology } & \multirow[t]{2}{*}{ Laterality } & \multicolumn{2}{|c|}{ Preoperative } & \multicolumn{3}{|c|}{ Follow-up } & \multirow[t]{2}{*}{ Outcomes } \\
\hline & & & & $\begin{array}{l}\text { ARCO } \\
\text { stage }\end{array}$ & HHS & $\begin{array}{l}\text { ARCO } \\
\text { stage }\end{array}$ & HHS & Survival(months) & \\
\hline 16 & $F / 35$ & Corticosteroid & Left & $\bigotimes a$ & 65 & $\triangle c$ & 50 & 46 & THA \\
\hline 17 & $\mathrm{M} / 49$ & Corticosteroid & Left & $\bigotimes a$ & 70 & $\triangle c$ & 42 & 44 & THA \\
\hline \multirow[t]{2}{*}{18} & $\mathrm{M} / 46$ & Alcoholism & Right & $\triangle c$ & 74 & प & 38 & 14 & THA \\
\hline & & & Left & $\bigotimes a$ & 60 & प & 45 & 14 & THA \\
\hline 19 & $M / 24$ & Idiopathic & Right & $\nabla \mathrm{b}$ & 70 & $\bigotimes a$ & 75 & 68 & $\begin{array}{l}\text { Collapse } \leq \\
2 \mathrm{~mm}\end{array}$ \\
\hline 20 & $\mathrm{M} / 42$ & Corticosteroid & Left & $\triangle a$ & 64 & प & 39 & 50 & THA \\
\hline 21 & $\mathrm{M} / 40$ & Alcoholism & Left & $\triangle c$ & 69 & प & 40 & 15 & THA \\
\hline 22 & $\mathrm{M} / 35$ & Alcoholism & Left & \a & 67 & $\triangle c$ & 49 & 45 & THA \\
\hline 23 & $M / 27$ & Corticosteroid & Left & $\bigotimes a$ & 75 & $\bigotimes a$ & 70 & 60 & $\begin{array}{l}\text { No } \\
\text { progression }\end{array}$ \\
\hline \multirow[t]{2}{*}{24} & $\mathrm{M} / 24$ & Corticosteroid & Right & $\bigotimes a$ & 77 & $\nabla b$ & 58 & 60 & $\begin{array}{l}\text { Advanced } \\
\text { collapse }\end{array}$ \\
\hline & & & Left & $\bigotimes a$ & 69 & $\nabla b$ & 53 & 60 & $\begin{array}{l}\text { Advanced } \\
\text { collapse }\end{array}$ \\
\hline 25 & $\mathrm{M} / 28$ & Idiopathic & Left & $\nabla \mathrm{b}$ & 78 & $\triangle a$ & 75 & 65 & $\begin{array}{l}\text { Collapse } \leq \\
2 \mathrm{~mm}\end{array}$ \\
\hline 26 & $\mathrm{M} / 34$ & Alcoholism & Left & $\triangle a$ & 57 & $\triangle c$ & 45 & 50 & THA \\
\hline 27 & $\mathrm{M} / 45$ & Corticosteroid & Left & $\bigotimes a$ & 55 & प & 35 & 26 & THA \\
\hline 28 & $\mathrm{M} / 41$ & Alcoholism & Right & $\triangle a$ & 59 & $\triangle c$ & 40 & 36 & THA \\
\hline 29 & $\mathrm{M} / 49$ & Corticosteroid & Left & $\bigotimes a$ & 50 & प & 38 & 13 & THA \\
\hline 30 & $F / 31$ & Corticosteroid & Left & $\bigotimes a$ & 51 & $\triangle c$ & 45 & 6 & THA \\
\hline \multirow[t]{2}{*}{31} & $F / 24$ & Corticosteroid & Right & $\bigotimes a$ & 56 & $\triangle c$ & 40 & 5 & THA \\
\hline & & & Left & $\triangle c$ & 81 & प & 37 & 36 & THA \\
\hline 32 & $\mathrm{M} / 44$ & Corticosteroid & Left & $\otimes b$ & 86 & प & 42 & 9 & THA \\
\hline \multirow[t]{2}{*}{33} & M/35 & Alcoholism & Right & $\nabla b$ & 80 & प & 38 & 34 & THA \\
\hline & & & Left & $\nabla c$ & 70 & प & 45 & 9 & THA \\
\hline
\end{tabular}

After anesthesia, patient laid in the supine position. The direct anterior approach (DAA) was taken to expose the anterolateral femoral head-neck junction. And then, osteotomies were used to create a bone window $(1.5 \mathrm{~cm}$ in width and length). With the aid of C-arm fluoroscopy images, the necrotic tissue was debrided using bone drills and curettes. A minimum of $5 \mathrm{~mm}$ subchondral bone was kept. A number of holes were made using a $3.2 \mathrm{~mm}$ drill to the extent that the surface of the sclerotic bone was observed to bleed. After debridement, the cavity was cleared by irrigation. The $\beta$-TCP sticks were impacted in layers. The original resected bone plate was grafted into the bone window without being fixed. Thorough sterilization with saline solution was carried out to prevent heterotopic ossification of the surgical site before the incision was closed. 
All patients received a strict post-operative rehabilitation plan under the guidance of an experienced doctor (Wei-guo Wang). Patients were instructed to do isometric quadriceps exercise immediately after the operation. It was advised to practice toetouching exercises in the course of first 3 months, and gradual weight-bearing was allowed for the subsequent 3 months with the aid of a cane or crutch on the opposite side. Patients began full weight-bearing in the 6th month after surgery. From the 12th post-operative month, patients were permitted to engage in high impact activities (such as running).

After surgery, clinical and radiological follow-up of all cases was conducted by the researchers of this study at the interval of 3 months in the first year and 6 months in the subsequent years. The clinical follow-up examined pain, function, deformity, and range of motion based on pre- and post-operative Harris Hip Score (HHS) difference [17]. The radiological follow-up consisted of radiographs taken at each visit from the antero-posterior and frog-leg lateral views of the bilateral hips. Clinical failure was defined as HHS $\leq 70$ points or conversion to THA for any reason. Radiographic failure was defined as the collapse $>2 \mathrm{~mm}$ or premature osteoarthritis according to follow-up radiographs. The time-to-failure was calculated as the time between the date of surgery and the date of clinical failure or radiographic failure. The onset time of head collapse was defined as the earliest period between the date of surgery and the date of follow-up discovering collapse progression.

The SPSS package for Windows (Version 20.0; SPSS Inc, Chicago, Illinois, USA) was applied for statistical analysis. The continuous variable was expressed as the mean \pm standard deviation. The Kolmogorov-Smirnov test was used to confirm the normality of the measured data. Wilcoxon test was performed to assess differences in HHS between pre- and post-operation. $P<0.05$ was considered to have statistical significance.

\section{Results}

All the 33 patients involved in this study were reviewed for a minimum period of 5 years and the mean follow-up was $66.1 \pm$ 4.3 months (range 60 months to 75 months). No perioperative complications were detected.

Preoperative HHS was $69.7 \pm 9.5$ points, and it was $52.0 \pm 16.1$ points at the final follow-up, indicating that clinical functions became poorer $(p<0.0001)$. On radiographs, only 4 hips $(8.5 \%)$ survived without further collapse, and collapse of the femoral head $\leq 2 \mathrm{~mm}$ was observed in the 8 hips (17.0\%) during 5-year follow-up. Meanwhile, 2 hips collapsed $>2 \mathrm{~mm}$ were awaiting for THA, 33 of 47 hips had converted to THAs in an average time-to-failure of $24.1 \pm 14.6$ months postoperatively. Gradual biodegradation of the $\beta$-TCP sticks without new bone formation was noted in the early postoperative period (Fig. 1). The average onset time of head collapse was $3.6 \pm 1.4$ months after surgery. Among the 33 hips converted to THAs, no complications occurred due to minimally invasive surgery. The resected femoral heads were sent for further examination. Gross examination showed the grafting bone substitute was muddy, and microscopic examination displayed only fibrotic and necrotic tissues in the femoral head without signs of new bone were observed (Fig. 2).

\section{Discussion}

The most important finding of this study was that "light-bulb" procedure grafting with $\beta$-TCP sticks was associated with a high failure rate for the treatment of pre-collapse and early post-collapse lesions NONFH. To our knowledge, this study is the first to report the poor results in the early postoperative period.

Generally, a genetic predisposition and exposure to risk factors exert a synergistic effect in the NONFH pathogenesis [18]. The impaired blood supply to the femoral head results in cellular apoptosis, subchondral fracture, and collapse at a later stage, subsequently deteriorate disabled osteoarthritis. Most authors believe that effective intervention at an early stage can successfully protect these hips from collapse $[19,20]$. The "light-bulb" technique obtains outstanding clinical efficacy, at a mean follow-up of 12 years, showing success in $84.6 \%$ (11) of 13 hips [10]. The success of this technique depends on replacing the necrotic segment with cortical bone graft plus fresh cancellous, achieving intra-osseous decompression of the necrotic segment, and providing adequate structural support in order to allow subchondral bone plate remodeling and healing. Mont et al. reported the utilization of bone morphogenetic protein-enriched allograft through the treatment with an

Page 6/12 
$86 \%$ success rate after a mean of 48 -months follow-up [21]. Another review of the "light-bulb" procedure using auto-iliac bone combination of demineralized bone matrix, at a mean follow-up of 25 months, stated $68 \%$ survivorship of 138 hips in early and medial stages of ONFH [22]. We detailed a similar procedure in which the necrotic bone was debrided through DAA and replaced by $\beta$-TCP sticks. We tended to determine whether a similar or high success rate could be obtained by using synthetic bone graft substitutes that avoided donor site morbidity.

Things turn out to be worse than we imagined. In this study, there was a high failure rate $(74.5 \%)$ on using $\beta$-TCP with advanced collapse and converting to THA. At 5 years of follow-up, the survivorship was $25.5 \%$, with 4 hips surviving without collapse of the femoral head and 8 hips collapse less than $2 \mathrm{~mm}$. The onset of head collapse was 3.6 months on average, and the first conversion to THA was performed at 5 months postoperative. From the appearance, the $\beta$-TCP grafts looked softened and muddy structure without new bone formation, when the specimens harvesting from the resected femoral head during THA.

$\beta$-TCP is a class of tunable calcium phosphate that has been widely used for bone grafting because of its excellent reliability, biocompatibility, and osteoconductive properties [23]. When employed for the treatment of NONFH, it may be a promising bioactive material because it can fill up the necrotic lesion, be degraded gradually by creeping substitution, and act as a scaffold for the repair of the osteonecrotic femoral head. In this study, it failed to treat NONFH successfully because of biodegradation immediately and lack of vascularization.

The $\beta$-TCP may have enough mechanical strength initially, but loses its structural support latterly due to degrade early after implantation. After removing the necrotic lesion, a bone cavity is produced in the femoral head. Theoretically, the degradation of bone grafts should be synchronized with the formation of new bone. The total biodegradation of $\beta$-TCP lasted over 12 weeks in a contained osseous defect [24]. During the process, a series of reactions including vascular infiltration, osteoid deposition, and restoration of the defect with new mineralized bone trabeculae occurred successively. A pilot study performed by Rijnen et al. showed that the absorption process of calcium phosphate cement took place in 6 weeks and was entirely completed in 12 weeks postoperatively [25]. Accelerated degradation leads to a rapid decrease of biomechanical strength in the necrotic site. As a result, these areas are prone to mechanical failure and fracture when stressed. A clinical trial conducted by Tomoki Aoyama et al. stated that the collapse of the femoral head was ascribed to the imbalance between the faster degradation of $\beta$-TCP and the weaker ability of osteogenesis [26].

Another possible reason is that the osteonecrotic environment in the femoral head is unfit for the $\beta$-TCP to repair the lesion. The vascular network is able to supply nutrients and remove waste products. Unlike autogenous bone tissues containing a highly vascularized network, current synthetic bone substitutes lack of vascularization, causing failure of the survivorship and function during the early phase of implantation [27]. There is accumulating evidence that the vascularized bone-grafting is crucial in the bone remodeling process [28]. Once a well-formed and stable small blood vessels incorporating into synthetic bone substitutes, the formation of new bone would be accelerated [29]. On the contrary, if the blood supply does not recover in time, $\beta$-TCP might undergo the necrotic process before integrating into the host body due to lack of nutrients and oxygen available within the constructs [30]. In a study of 19 hips managed with non-vascularized bone-grafting using injectable synthetic bone graft substitutes through a core track for the treatment of ONFH (ARCO IIC and IIIA), survivorship was $10.5 \%$ in the 5-year follow-up [31]. By contrast, vascularized bone grafting has resulted in excellent outcomes that many studies reported a 5 years survivorship was approximately $80 \%$ [32]. In a study on $\beta$-TCP granules mixed with vascularized iliac bone graft cultured with mesenchymal stem cells in 9 hips, 7 patients had no evidence of progression at a mean followup of 24 months [26]. Additionally, $\beta$-TCP lacks biological stimulatory activity [33]. All these factors indicate that $\beta$-TCP is not an optimal biomaterial to be applied in the treatment of NONFH.

The limitations of this study include a small sample size without controls and its non-randomized study design. Whether the use of the $\beta$-TCP or other synthetic materials grafting is effective in other cases of NONFH cannot be answered by this study. Because of the poor results, we discontinued to recommend our patients on using light-bulb procedure combined with $\beta$-TCP sticks grafting in the treatment of NONFH. Further larger prospective random control trials are required to better validate our 
findings. Evaluation of magnetic resonance imaging, arthroscopic assessment of regenerated cartilage, and histological evaluation should be performed for all subjects at a certain period after surgery. Additionally, new tissue scaffolds such as bone graft substitutes combined with growth factors, and pre-vascularization bio-engineered bone may increase the survivorship of bone grafting [34].

\section{Conclusion}

Treatment of NONFH with "light-bulb" and $\beta$-TCP sticks did not avoid or forestall the need for hip replacement. Therefore, it is not proposed for the treatment of pre-collapse and early post-collapse lesions NONFH.

\section{Abbreviations}

ARCO: Association Research Circulation Osseous; $\beta$-TCP: beta-tricalcium phosphate; CD: core decompression; DAA: direct anterior approach; HHS: Harris Hip Score; NONFH: Non-traumatic osteonecrosis of femoral head; THA: Total hip arthroplasty.

\section{Declarations}

\section{Acknowledgements}

The authors have no acknowledgements to make.

\section{Authors' contributions}

All authors have read and approved the manuscript in its current state. Conceptualization: Pei Liu, Xiao-hong Mu, Wan-shou Guo. Data curation: Pei Liu, Hua-chen Yu, Jian-lei, Guan. Formal analysis: Hua-chen Yu, Jian-lei, Guan. Investigation: Qi-dong Zhang, Zhao-hui Liu, Wei-guo Wang. Methodology: Pei Liu, Qi-dong Zhang, Zhao-hui Liu, Wei-guo Wang. Project administration: Pei Liu, Qi-dong Zhang, Xiao-hong Mu, Wan-shou Guo. Validation: Xiao-hong Mu, Wan-shou Guo. Writing original draft: Pei Liu. Writing - review \& editing: Pei Liu, Xiao-hong Mu, Wan-shou Guo.

\section{Funding}

This work was supported by grants from the National Natural Science Foundation of China (No. 81703896, 81673776), Beijing municipal science and technology commission (No. Z171100001017209), and National Key Research and Development Program of China (No. 2017YFC0108102).

\section{Availability of data and materials}

The datasets used and/or analyzed during the current study are available from the corresponding author on reasonable request.

\section{Ethics approval and consent to participate}

This study was approved by the Ethics Committee of the China-Japan Friendship Hospital (2015-SFZX-N). The consent form was in written format.

\section{Consent for publication}

All patients provided consent to participate in this study, per our institution's standard for research consent forms, this consent specified that the research information obtained may be used for publication.

\section{Competing interests}


The authors have no disclosures, conflicts of interest, or competing interests to make.

\section{Author details}

${ }^{1}$ Beijing University of Chinese Medicine, Yinghuadong Road, Chaoyang District, Beijing, China.

${ }^{2}$ Beijing University of Chinese Medicine, Dongzhimen Hospital, Department Orthopedics 4, Beijing, China.

${ }^{3}$ Graduate School of Peking Union Medical College, Beijing, China.

${ }^{4}$ Department of Orthopaedic Surgery, Beijing Key Lab Immune-Mediated Inflammatory Diseases, China-Japan Friendship Hospital, Yinghuadong Road, Chaoyang District, Beijing, China.

\section{References}

1. Powell C, Chang C, Gershwin ME. Current concepts on the pathogenesis and natural history of steroid-induced osteonecrosis. Clin Rev Allergy Immunol. 2011;41:102-113.

2. Mont MA, Zywiel MG, Marker DR, McGrath MS, Delanois RE. The natural history of untreated asymptomatic osteonecrosis of the femoral head: a systematic literature review. J Bone Joint Surg Am. 2010;92:2165-2170.

3. Cohen-Rosenblum A, Cui Q. Osteonecrosis of the femoral head. Orthopedic Clinics of North America. 2019;50:139-149.

4. Brown PJ, Mannava S, Seyler TM, Plate JF, Van Sikes C, Stitzel JD, Lang JE. Multiple small diameter drillings increase femoral neck stability compared with single large diameter femoral head core decompression technique for avascular necrosis of the femoral head. Surg Technol Int. 2016;29:247-254.

5. Pierce TP, Elmallah RK, Jauregui JJ, Poola S, Mont MA, Delanois RE. A current review of non-vascularized bone grafting in osteonecrosis of the femoral head. Curr Rev Musculoskelet Med. 2015;8:240-245.

6. Tanaka R, Yasunaga Y, Fujii J, Yamasaki T, Shoji T, Adachi N. Transtrochanteric rotational osteotomy for various hip disorders. J Orthop Sci. 2019;24:463-468.

7. Morita D, Hasegawa Y, Okura T, Osawa Y, Ishiguro N. Long-term outcomes of transtrochanteric rotational osteotomy for non-traumatic osteonecrosis of the femoral head. Bone Joint J. 2017;99-B:175-183.

8. Sultan AA, Khlopas A, Surace P, Samuel LT, Faour M, Sodhi N, Krebs VE, Stearns KL, Molloy RM, Mont MA. The use of non-vascularized bone grafts to treat osteonecrosis of the femoral head: indications, techniques, and outcomes. Int Orthop.2019;43: 1315-1320.

9. Zhao D, Xie H, Xu Y, Wang Y, Yu A, Liu Y, Wang A, He W, Wang X, Li Z, Sun W, Tian S, Wang B, Liu B. Management of osteonecrosis of the femoral head with pedicled iliac bone flap transfer: A multicenter study of 2190 patients. Microsurgery. 2017;37:896-901.

10. Rosenwasser MP, Garino JP, Kiernan HA, Michelsen CB. Long term followup of thorough debridement and cancellous bone grafting of the femoral head for avascular necrosis. Clin Orthop Relat Res. 1994:17-27.

11. Dimitriou R, Mataliotakis GI, Angoules AG, Kanakaris NK, Giannoudis PV. Complications following autologous bone graft harvesting from the iliac crest and using the RIA: a systematic review. Injury. 2011;42 Suppl 2:S3-S15.

12. Baldwin P, Li DJ, Auston DA, Mir HS, Yoon RS, Koval KJ. Autograft, allograft, and bone graft substitutes: clinical evidence and indications for use in the setting of orthopaedic trauma surgery. J Orthop Trauma. 2019;33: 203-213.

13. Shamsoddin E, Houshmand B, Golabgiran M. Biomaterial selection for bone augmentation in implant dentistry: A systematic review. J Adv Pharm Technol Res. 2019;10:46-50.

14. Kumagai H, Makihara T, Funayama T, Sato K, Noguchi H, Abe T, Koda M, Yamazaki M. Angiogenesis and new bone formation in novel unidirectional porous beta-tricalcium phosphate: a histological study. J Artif Organs. 2019;22(4):294-

Page $9 / 12$ 
299.

15. Li B, Hu R, Sun L, Luo R, Zhao J, Tian X. A CARE-compliant article: Biomechanics of treating early-stage femoral-head osteonecrosis by using a beta-tricalcium phosphate bioceramic rod system: a 3-dimensional finite-element analysis. Medicine (Baltimore). 2018;97:e10808.

16. Gardeniers J. A new international classification of osteonecrosis of the ARCO committee on teminology and classification. ARCO New Letter. 1992:41-46.

17. Harris WH. Traumatic arthritis of the hip after dislocation and acetabular fractures: treatment by mold arthroplasty. An end-result study using a new method of result evaluation. J Bone Joint Surg Am. 1969;51:737-755.

18. Chughtai M, Piuzzi NS, Khlopas A, Jones LC, Goodman SB, Mont MA. An evidence-based guide to the treatment of osteonecrosis of the femoral head. Bone Joint J. 2017;99-B:1267-1279.

19. Sultan AA, Khlopas A, Surace P, Samuel LT, Faour M, Sodhi N, et al. The use of non-vascularized bone grafts to treat osteonecrosis of the femoral head: indications, techniques, and outcomes. Int Orthop. 2019;43:1315-1320.

20. Petek D, Hannouche D, Suva D. Osteonecrosis of the femoral head: pathophysiology and current concepts of treatment. EFORT Open Reviews. 2019;4:85-97.

21. Mont MA, Etienne G, Ragland PS. Outcome of nonvascularized bone grafting for osteonecrosis of the femoral head. Clin Orthop Relat Res. 2003:84-92.

22. Wang B, Sun W, Shi Z, Zhang N, Yue D, Guo W, Shi S, Li Z. Treatment of nontraumatic osteonecrosis of the femoral head using bone impaction grafting through a femoral neck window. Int Orthop. 2010;34(5):635-639.

23. Dorozhkin SV, Epple M. Biological and medical significance of calcium phosphates. Angew Chem Int Ed Engl. 2002;41:3130-3146.

24. Turner TM, Urban RM, Gitelis S, Kuo KN, Andersson GB. Radiographic and histologic assessment of calcium sulfate in experimental animal models and clinical use as a resorbable bone-graft substitute, a bone-graft expander, and a method for local antibiotic delivery. One institution's experience. J Bone Joint Surg Am. 2001;83-A Suppl 2:8-18.

25. Rijnen WH, Gardeniers JW, Schreurs BW, Buma P. Impacted bone and calcium phosphate cement for repair of femoral head defects: a pilot study. Clin Orthop Relat Res. 2007;459:216-221.

26. Aoyama T, Goto K, Kakinoki R, Ikeguchi R, Ueda M, Kasai Y, Maekawa T, Tada H, Teramukai S, Nakamura T, Toguchida J. An exploratory clinical trial for idiopathic osteonecrosis of femoral head by cultured autologous multipotent mesenchymal stromal cells augmented with vascularized bone grafts. Tissue Eng Part B Rev. 2014;20(4):233-242.

27. Samavedi S, Whittington AR, Goldstein AS. Calcium phosphate ceramics in bone tissue engineering: a review of properties and their influence on cell behavior. Acta Biomater. 2013;9:8037-8045.

28. Lafage-Proust MH, Roche B, Langer M, Cleret D, Vanden BA, Olivier T, Vico L. Assessment of bone vascularization and its role in bone remodeling. Bonekey Rep. 2015;4:662.

29. Bian W, Li D, Lian Q, Zhang W, Zhu L, Li X, Jin Z. Design and fabrication of a novel porous implant with pre-set channels based on ceramic stereolithography for vascular implantation. Biofabrication. 2011;3(3):34103.

30. Nguyen LH, Annabi N, Nikkhah M, Bae H, Binan L, Park S, Kang Y, Yang Y, Khademhosseini A. Vascularized bone tissue engineering: approaches for potential improvement. Tissue Eng Part B Rev. 2012;18(5):363-382.

31. Yu PA, Peng KT, Huang TW, Hsu RWW, Hsu WH, Lee MS. Injectable synthetic bone graft substitute combined with core decompression in the treatment of advanced osteonecrosis of the femoral head: A 5-year follow-up. Biomed J. 2015;38(3):257-261.

32. Mont MA, Cherian JJ, Sierra RJ, Jones LC, Lieberman JR. Nontraumatic osteonecrosis of the femoral head: where do we stand today? A ten-year update. J Bone Joint Surg Am. 2015;97:1604-1627.

33. Alvarez LM, Rivera JJ, Stockdale L, Saini S, Lee RT, Griffith LG. Tethering of epidermal growth factor (EGF) to beta tricalcium phosphate ( $\beta$-TCP) via fusion to a high affinity, multimeric $\beta$ TCP-binding peptide: effects on human multipotent stromal cells/connective tissue progenitors. PLoS One. 2015;10:e129600.

Page $10 / 12$ 
34. Liu J, Chuah YJ, Fu J, Zhu W, Wang DA. Co-culture of human umbilical vein endothelial cells and human bone marrow stromal cells into a micro-cavitary gelatin-methacrylate hydrogel system to enhance angiogenesis. Mater Sci Eng C Mater Biol Appl. 2019;102:906-916.

\section{Figures}


\section{Figure 1}

A 24 year-old female patient (case 31): (A-C) Preoperative radiographs showed bilateral NONFH with right ARCO \a stage and left ARCO $₫ c$ stage. (D-F) Postoperative imaging at one week exhibited adequate filling of the osteonecrotic lesion by the beta-tricalcium phosphate ( $\beta$-TCP). (G-I) At eight weeks, the right head presented advanced collapse, and the $\beta$-TCP were gradually absorbed. Also, heterotopic ossification was observed in right side. (J-L) At twenty weeks, the right femoral head collapsed more than $4 \mathrm{~mm}$ and the contralateral collapsed less than $2 \mathrm{~mm}$. In the meantime, the sparse remnants of grafting materials were almost entirely degraded. 




\section{Figure 2}

$\beta$-TCP in the grafting area was muddy, and only fibrotic and necrotic tissues in the femoral head without signs of new bone were observed. 